\title{
Campo político a partir da perspectiva de Bourdieu e do poder: implicações no campo jornalístico
}

\author{
Campo político desde la perspectiva y el poder de Bourdieu: \\ implicaciones en el campo periodístico \\ Political field from Bourdieu's perspective and power: implications \\ in the journalistic field
}

Thaíze Ferreira da Luz ${ }^{1}$

\begin{abstract}
Resumo
Acreditamos que para compreender o funcionamento de regimes e instituições, é fundamental estudarmos o campo político e suas implicações sociais e culturais, como parte do processo de consolidação das democracias. Conhecer os elementos que formam e delimitam a cultura política de uma sociedade é tarefa fundamental para compreender como funcionam suas instituições políticas e os fatores que legitimam os agentes políticos que controlam tal sociedade. Nesse sentido, trabalharemos aqui com a perspectiva de poder definida por Pierre Bourdieu, cujo entendimento é de que o poder só pode ser exercido mediante capital e no interior do próprio campo. Ou seja, dentro do campo político. E a posição dominante dentro do campo político está intimamente ligada a sua maior acumulação de capital, seja ele cultural, intelectual, econômico ou representado nas suas mais diversas formas, podendo ou não, estar acumulado. Desta forma, é pertinente ressaltar a necessidade de distinguir o campo de produção do campo de consumo no entendimento das ocorrências políticas. Na mesma linha, quando pensamos nos grandes grupos midiáticos existentes no Brasil, em especial os jornais por nós analisados - $O$ Globo e $O$ Estado de São Paulo - verificamos que o poder simbólico exercido pelo campo jornalístico, é capaz de legitimar discursos e influenciar as massas, interferindo assim, nas questões políticas. Deste modo, pretendemos analisar o conceito político a partir da perspectiva de Pierre Bourdieu, bem como, o poder simbólico dos impressos e suas implicações nos processos eleitorais.
\end{abstract}

Palavras- Chave: Política; Poder; Pierre Bourdieu; Campo jornalístico; Poder simbólico.

\section{Resumen}

Creemos que para comprender el funcionamiento de los regímenes e instituciones, es esencial estudiar el campo político y sus implicaciones sociales y culturales como parte del proceso de consolidación de las democracias. Conocer los elementos que forman y delimitan la cultura política de una sociedad es una tarea fundamental para comprender cómo funcionan sus instituciones políticas y los factores que legitiman a los agentes políticos que controlan dicha sociedad. En este sentido, trabajaremos aquí, con la perspectiva del poder definida por Pierre Bourdieu, cuyo entendimiento es que el poder solo puede ejercerse a través del capital y dentro del campo mismo. Es decir, dentro del campo político. Y la posición dominante dentro del campo político está estrechamente vinculada a su mayor acumulación de capital, ya sea cultural, intelectual, económico o representado en sus formas más diversas, ya sea que se acumule o no. Por lo tanto, es pertinente enfatizar la necesidad de distinguir el campo de producción del campo de consumo en la comprensión de los acontecimientos políticos. En la misma línea, cuando pensamos en los grandes grupos de medios en Brasil, especialmente en los periódicos que analizamos, O Globo y O Estado de São Paulo, encontramos que el poder simbólico ejercido por el campo periodístico es capaz de legitimar los discursos e influir en las masas. Interfiriendo así con cuestiones políticas. De esta manera, pretendemos analizar el concepto político desde la

\footnotetext{
${ }^{1}$ Doutoranda em História pela Pontifícia Universidade Católica do Rio Grande do Sul (PUCRS); Rio Grande; Rio Grande do Sul; Brasil; e-mail: thaizefl@gmail.com; O presente trabalho foi realizado com apoio da Coordenação de Aperfeiçoamento de Pessoal de Nível Superior - Brasil (CAPES) - Código de Financiamento 001; This study was financed in part by the Coordenação de Aperfeiçoamento de Pessoal de Nível Superior Brasil (CAPES) - Finance Code 001.
} 
perspectiva de Pierre Bourdieu, así como el poder simbólico del material impreso y sus implicaciones en los procesos electorales.

Palabras claves: Política; Poder; Pierre Bourdieu; Campo periodístico; Poder simbólico

\begin{abstract}
We believe that in order to understand the functioning of regimes and institutions, it is essential to study the political field and its social and cultural implications as part of the process of consolidating democracies. Knowing the elements that form and delimit the political culture of a society is a fundamental task to understand how its political institutions work and the factors that legitimize the political agents that control such society. In this sense, we will work here, with the perspective of power defined by Pierre Bourdieu, whose understanding is that power can only be exercised through capital and within the field itself. That is, within the political field. In addition, the dominant position within the political field is closely linked to its greater accumulation of capital, be it cultural, intellectual, economic or represented in its most diverse forms, whether or not it may be accumulated. Thus, it is pertinent to emphasize the need to distinguish the field of production from the field of consumption in understanding political occurrences. In the same vein, when we think of the large media groups in Brazil, especially the newspapers we analyzed - O Globo and O Estado de São Paulo - we find that the symbolic power exercised by the journalistic field is able to legitimize discourses and influence the masses. Thus interfering with political issues. In this way, we intend to analyze the political concept from Pierre Bourdieu's perspective, as well as the symbolic power of the printed matter and its implications in the electoral processes.
\end{abstract}

Key-words: Politics; Power; Pierre Bourdieu; Journalistic field; Symbolic power.

\title{
1. Introdução
}

Nesse artigo apresentamos um recorte teórico dentro de nossa pesquisa de doutorado a qual analisa o candidato Fernando Collor de Mello, vitorioso nas eleições presidenciais de 1989, observando a construção de sua trajetória política até a perda do cargo de presidente em 1992. Nosso marco temporal é entre os anos de 1987 e 1992 e temos como objeto e fonte de pesquisa, os jornais O Globo e O Estado de São Paulo².

Nosso referencial teórico é baseado em conceitos de poder; campo político; campo jornalístico e poder simbólico de Pierre Bourdieu. Acreditamos que o campo político e o campo jornalístico no Brasil possuem uma realidade bem diferente da realidade francesa, cuja análise de Bourdieu foi descrita. Em nosso país pode ser difícil separar o campo político do campo jornalístico, e a primeira eleição pós o regime civil militar de 1964 é marcada justamente por uma forte atuação da imprensa brasileira. Porém, o crescente número de trabalhos acadêmicos que usam a imprensa como fonte para a análise de processos eleitorais, mostra que este é um campo muito profícuo e que possibilita debates muito construtivos.

\footnotetext{
${ }^{2}$ Nossa pesquisa nos periódicos supracitados foi montada com base em um cronograma elegendo marcos chaves do período.Utilizamos o método de análise de conteúdo preferencialmente do conteúdo opinativo desses jornais, observando os editoriais e colunas não assinadas do caderno O País de O Globo e os cadernos Política e Economia de O Estado de São Paulo. Nesse artigo, nossa intenção é apresentar um conteúdo a respeito do referencial teórico empregado na pesquisa, como forma de exemplificar a utilização de conceitos chaves de Pierre Bourdieu em pesquisas que relacionam política e imprensa. Assim, não nos ateremos em discorrer sobre a metodologia da pesquisa.
} 
Neste sentido, trataremos aqui de apresentar um estudo de caso utilizando alguns conceitos principais de Pierre Bourdieu, com a finalidade de exemplificar a possiblidade de trabalho empregando esse autor em estudos que envolvem política e imprensa no Brasil.

\section{O conceito de campo de Pierre Bourdieu: uma breve análise do campo político e do campo jornalístico}

Nossa pesquisa desenvolvida dentro do campo político, onde analisa os mecanismos de dominação dentro desse campo para a imposição de um candidato vitorioso no pleito eleitoral de 1989 e sua tentativa de manter-se no poder, também insere-se no campo jornalístico, representando o lugar de fala do político, onde este fala para a imprensa e analisando a própria função da imprensa enquanto imposição de legitimidade para produzir um discurso político.

Nesse sentido, trabalharemos aqui com a perspectiva de poder definida por Pierre Bourdieu, o qual entende que o poder só pode ser exercido mediante capital e no interior do próprio campo. Ou seja, dentro do campo político e dentro do campo jornalístico. De maneira que a posição dominante dentro do campo, está intimamente ligada a sua maior acumulação de capital específico, seja ele cultural, intelectual, econômico ou representado nas suas mais diversas formas, podendo ou não estar acumulado, conforme Bourdieu (2016).

Antes de avançarmos é pertinente esclarecer o conceito de campo a partir da teoria de Bourdieu. $\mathrm{O}$ autor parte da premissa de que precisamos pensar a realidade das relações em sociedade, ou seja, a "realidade social" como um lugar de disputas, um espaço de lutas simbólicas promovido pelos agentes, ou seja, os sujeitos que compõem a vida social. As posições ocupadas pelos agentes dentro dos diferentes tipos de campo social (político; artístico; econômico, jornalístico, literário, etc.) e o que acontece dentro deste campo, é limitado pelas condições do próprio campo. Desta forma, apenas quem pertence a um determinado campo, é capaz de entender a dinâmica própria dele. (ORTIZ, 1983, p. 18-20).

Seguindo o pensamento de Bourdieu, o campo político é um campo carregado de poder simbólico. $\mathrm{O}$ campo ${ }^{3}$ possui regras próprias, onde apenas determinados indivíduos são legitimados para exercer a atividade política:

\footnotetext{
${ }^{3} \mathrm{O}$ campo é caracterizado por quatro leis fundamentais: "Primeira: para existir um campo, deve existir interesses específicos que são irredutíveis, isto é, nenhum outro campo é capaz de supri-los; Segunda: todo campo possui regras e leis próprias para o seu funcionamento e os agentes que quiserem fazer parte dele, devem estar dispostos a aceitar essas regras e leis, além de serem capazes de entende-las; Terceira: O estado da luta e quantidade e qualidade de capital, definem a estrutura do campo; Quarta: a existência do próprio campo é um interesse em comum a todos os agentes que dele pertencem". (Bourdieu, 1983, p. 89)
} 


\begin{abstract}
A intenção política só se constitui na relação com um estado do jogo político e, mais precisamente, do universo das técnicas de ação e de expressão que ele oferece em dado momento. Neste caso, como em outros, a passagem do implícito ao explícito, da impressão subjetiva à expressão objetiva, à manifestação pública num discurso ou num ato público constitui por si um ato de instituição e representa por isso uma forma de oficialização, de legitimação (...). (BOURDIEU, 2016, p. 165).
\end{abstract}

Da mesma maneira, ocorre no campo jornalístico. Há uma disputa pelo monopólio legítimo da produção da notícia e dos discursos, em especial aqui, o discurso político através da imprensa, em que diferentes veículos de comunicação concorrem na busca pelo reconhecimento (legitimidade) por parte de seus leitores, anunciantes e assinantes.

Essa disputa simbólica, dentro dos campos, dá-se justamente pela capacidade de seus agentes em monopolizar a produção dos bens simbólicos (a legitimidade do discurso político pelos políticos; a legitimidade da produção jornalística nos jornais). O campo possui uma hierarquia própria, em que sujeitos capazes de produzir um bem com valor simbólico, são os detentores de capital simbólico ou dominantes dentro do campo em que estão inseridos. E o que determina a posição de dominação dos sujeitos dentro do campo, é justamente o acúmulo de capital que ele consegue ter.

Esse poder simbólico do campo político, se constitui na medida em que são criados mecanismos capazes de despertar nos eleitores uma espécie de "oferta e procura", fruto das ideias defendidas entre diferentes candidatos, como "problemas, programas, análises, comentários, conceitos, acontecimentos", levando os cidadãos a agirem como se fossem consumidores, comprando a melhor opção apresentada na disputa eleitoral. (BOURDIEU, 1989, p.164).

Assim, os políticos fazem o duplo jogo da política: criam as demandas e apresentam soluções para essas demandas (BOURDIER, 2016, p. 173-177). No caso específico de nossa pesquisa, Collor é um ótimo exemplo desta prática. Apresentou em sua agenda política as principais demandas do Brasil naquele contexto, as quaisacabaram sendo utilizadas na agenda da imprensa, e criou a imagem de mito "Salvador da Pátria", ou seja, definindo-se como o único político habilitado para resolver os problemas que a Nação enfrentava.

Todavia, Collor de Mello não foi capaz de manter-se numa posição dominante dentro do campo político, ocasionando o fim de seu mandato enquanto presidente precocemente. Isto se deu porque a estrutura do campo político está em constante transformação, e um agente dominante em determinado contexto social, pode não mais ocupar esta posição. Desta forma, todo o capital específico que o político possui, que lhe confere a capacidade de legitimidade para falar em nome desse campo, pode ser abalada por outros fatores. Neste caso específico, 
escândalos de corrupção foram o pretexto para que seu poder chegasse ao fim, conforme exemplifica Bourdieu:

O campo político é o lugar por excelência de exercício do capital simbólico: é um lugar em que existir, ser, é ser percebido. Um político é, em grande medida, um homem conhecido e reconhecido; não é um acaso se os políticos são particularmente vulneráveis ao escândalo, sendo o escândalo gerador de descrédito, e o descrédito é o inverso da acumulação do capital simbólico. (BOURDIEU, 2014, p. 353).

Por esse motivo, faz-se necessário entender a relação entre o campo político com outros espaços de disputa, como em especial, o campo jornalístico. É na imprensa que temos o principal meio de divulgação de escândalos, podendo assim, afetar diretamente o capital simbólico acumulado pelos políticos, como no caso de Fernando Collor de Mello.

E é justamente através do poder simbólico que os agentes pertencentes a um determinado campo, no caso os políticos dentro do campo político, transformam capital em poder e meio de dominação, pois Bourdieu define que "o poder simbólico, poder subordinado, é uma forma transformada, quer dizer, irreconhecível, transfigurada e legitimada, das outras formas de poder" (BOURDIEU, 1989, p. 15).

Outra autora que corrobora com este entendimento - Céli Pinto quando define o campo político como um campo de luta: "A luta política é a luta simbólica por excelência ${ }^{4}$, pois seu principal objetivo é converter, é o fazer crer que sua proposta é a melhor para todos: transformar os interesses localizados de grupo, isto é, de classe ou fração de classe, em interesses gerais". (PINTO, 1996, p.225).

Desta forma, é pertinente ressaltar a necessidade de distinguir o campo de produção do campo de consumo no entendimento das ocorrências políticas. Pois, sendo o campo de produção aquele em que os agentes políticos procuram impor sua visão de mundo para tomar o Estado, "os diversos capitais se transformam em capital político que em uma democracia pode ser traduzido pela capacidade dos agentes de conseguirem votos" (PINTO, 1996, p. 226).

Ou seja, ocorre claramente uma transferência de capital de um campo para outro, pois a habilidade de conseguir os votos é fruto do poder simbólico dos agentes políticos que fazem parte do campo político, e seu poder simbólico, advém da “conversão de capitais acumulados

\footnotetext{
${ }^{4}$ Neste caso, não significa que os demais campos não sejam também campos de luta. Todavia, "quando se fala de política fala-se de um campo de poder por excelência. Em que este campo de poder se distingue dos demais campos, uma vez que em última instância todos os campos envolvem luta e força? Distinguem-se por ser um espaço de luta pelo poder em si” (PINTO, 1996, p. 225).
} 
e transformados em poder, na grande maioria das vezes em outros campos que não só o político" (PINTO, 1996, p. 226).

$\mathrm{Na}$ mesma linha, quando pensamos nos grandes grupos midiáticos existentes no Brasil, em especial os jornais por nós analisados - O Globo e O Estado de São Paulo, verificamos que o poder simbólico ${ }^{5}$ exercido pelo campo jornalístico, é capaz de legitimar discursos, assim, "o que faz o poder das palavras e das palavras de ordem, poder de manter a ordem ou de a subverter, é a crença na legitimidade das palavras e daquele que as pronuncia, crença cuja produção não é da competência das palavras”. (BOURDIEU, 1989, p. 15).

Ainda segundo o autor:

o mundo do jornalismo é um microcosmo que tem leis próprias e que é definido por sua posição no mundo global e pelas atrações e repulsões que sofre da parte dos outros microcosmos. Dizer que o que nele se passa não tem sua própria lei, significa dizer que o que nele se passa não pode ser compreendido de maneira direta a partir de fatores externos. (BOURDIEU, 1997, p. 55).

Dentro desta perspectiva, a atuação do campo jornalístico é relativamente autônoma. Essa relatividade decorre do fato que esse campo está condicionado a lidar com pressões externas, relacionadas à atuação política do Estado, e a questões de ordem econômicas, como os anunciantes, seu público leitor e a própria concorrência com outros órgãos de imprensa; sendo assim, seu maior ou menor grau de autonomia estará condicionado às pressões em seu campo de produção. É necessário conceituar aqui a noção de campo de atuação, de forma que, ao trabalharmos com o jornalismo enquanto objeto de pesquisa, devemos observar que a produção do discurso político fica concentrada nas mãos de agentes capazes e legitimados para produzi-lo, como jornais; partidos políticos; líderes políticos, etc ${ }^{6}$.

Tomemos como exemplo o caso brasileiro, em que a imprensa muitas vezes dependeu de contratos com o Estado para financiamento e expansão de suas empresas jornalísticas, somados aos períodos de censura, que limitaram ou até mesmo extinguiram inúmeros veículos midiáticos (SODRÉ, 1999; MARTINS, A. e LUCA, T., 2013), mostrando essa relativa autonomia do campo jornalístico, sofrendo uma pressão de outros campos, como o campo político e o campo econômico. Todavia, a estrutura própria do campo jornalístico lhe confere a habilidade de usar estratégias para se manter enquanto campo, preservando certo

\footnotetext{
${ }^{5}$ O poder simbólico, segundo BOURDEIU, é "um poder de construção da realidade que tende a estabelecer uma ordem gnosiológica: o sentido imediato do mundo (e, em particular, do mundo social) supõe aquilo a que Durkheim chama conformismo lógico, quer dizer 'uma concepção homogênea do tempo, do espaço, do número, da causa, que torna possível a concordância entre inteligências". (BOURDIEU, 1989, p. 9).

${ }^{6}$ Ver: BOURDIEU, Pierre. A distinção, crítica social do julgamento. 1. a edição. São Paulo: EDUSP, 2007.
} 
grau de autonomia. Desta maneira, o campo jornalístico acaba legitimando-se como um dos lugares de produção do discurso político.

O discurso político é altamente hierarquizado e excludente. Dotado de uma linguagem específica, que se afasta do homem comum, a participação na política acaba sendo feita por uma pequena parcela da população que consegue absorver as regras próprias do campo político. Os cidadãos acabam delegando, ainda que de forma inconsciente, o poder político nas mãos de agentes que eles entendem serem mais preparados e capacitados para tratarem as questões políticas.

Isto é possível graças ao poder simbólico dos campos político e jornalístico, que se constituem à medida em que são criados mecanismos capazes de despertarem nos eleitores, uma espécie de "oferta e procura", fruto das ideias defendidas entre diferentes candidatos, como "problemas, programas, análises, comentários, conceitos, acontecimentos", levando os cidadãos a agirem como se fossem consumidores, comprando a melhor opção apresentada na disputa eleitoral. (BOURDIEU, 1989, p. 164).

Assim, levamos em conta para esta análise, a tradição clientelista predominante no Brasil, de forma que:

em sua história política, tendo passado por experiências populistas e autoritárias e estando agora ensaiando viver em um regime democrático, seria bastante interessante analisar a composição do capital do campo político historicamente e até a própria constituição do campo enquanto espaço de interesses irredutíveis ao longo do tempo". (PINTO, 1996, p.227).

Deste modo, o sistema político brasileiro é visto como um sistema restrito, numa arena de disputa onde os recursos são escassos e disputados por classes, grupos sociais e instituições correspondentes, tendo suas ações reflexo na sociedade brasileira, sendo o patrimonialismo uma característica estrutural do sistema político no Brasil, onde o vínculo entre os detentores do poder e as lideranças políticas emergentes fazem com que o direito de exercer a política passe a ser um benefício outorgado. (SCWATZMAN, 1982, p. 60).

Da mesma forma, a cooptação política, um elemento próprio do campo político, faz com que quanto maior for a participação do líder na burocracia governamental, maior será sua força política. O que na prática significa garantir mais recursos para sua classe. E isso deve-se ao fato de que a política tradicional brasileira é "urbana, moderna e conduzida por uma elite com refinamento e habilidade necessários para controlar um aparelho estatal bastante complexo". (SCWATZMAN, 1982, p. 61). 
Com relação à situação da imprensa brasileira, também temos um caso bem peculiar, pois diferentemente de outros países, como os Estados Unidos por exemplo, onde a imprensa é formado por empresas jornalísticas nas quais qualquer pessoa pode ser detentora de suas ações, no Brasil, os grandes grupos midiáticos pertencem a famílias tradicionais, e operam num sistema de concessões dadas pelo governo.

Verifica-se que o campo jornalístico brasileiro, tem sua autonomia bastante reduzida, uma vez que, as pressões externas ao seu campo influenciam de maneira direta no funcionamento das empresas jornalísticas. É comum vermos a participação de colunistas que acabam ganhando prestígio de seus leitores e se lançam na carreira política. O mesmo ocorre com políticos que possuem a concessão para operar rádios e emissoras de televisão, ou são proprietários de jornais locais, os quais utilizam sua ideologia política para influenciar nas pautas desses veículos de informação.

Podemos usar nesse caso, a questão da homologia estrutural entre o campo político como campo de produção de demandas e o campo jornalístico, enquanto consumidor dessas demandas. No caso brasileiro verificamos que os agentes dominantes desses dois campos, possuem habitus $^{7}$ compartilhados, tendo em vista a natureza de seus interesses, pela necessidade de manterem-se no domínio do monopólio da produção de bens simbólicos dentro de seus campos.

\section{Os jornais O Globo e O Estado de São Paulo, um estudo de caso sobre o poder simbólico e a eleição de Fernando Collor de Mello em 1989}

No Brasil, as eleições de 1989 serviram como marco para que estudos relacionados à influência da mídia na política começassem a ser desenvolvidos, justamente pela experiência das eleições presidenciais. Após a ditadura civil militar e o retorno da liberdade de imprensa, os meios de comunicação puderam desenvolver seus discursos mais livremente. Porém, ainda são poucos os pesquisadores, em especial no campo da História, que se voltam para esse período e esse tipo de fonte histórica como objeto de pesquisa. A imprensa, durante a

\footnotetext{
${ }^{7} \mathrm{O}$ que determina as práticas classificatórias em sociedade e, por consequência, as posições ocupadas pelos agentes nesse espaço de representação abstrata das relações sociais chamado de campo, é o habitus de cada agente que dele faz parte. O habitus por sua vez, está classificado como primário, aquele adquirido pelo nascimento até pouco antes do sujeito ingressar na escola. Nesse momento, as condições sociais, econômicas, culturais, de raça e gênero, por exemplo, formarão às referências do agente e servirão de orientação para os seus interesses e gostos. Porém, o habitus secundário, ou seja, aquele conjunto de conhecimentos adquiridos entre a escola e a universidade, pode alterar esses interesses, fazendo com que o agente passe a se interessar por outros bens simbólicos. (BOURDIEU, 2016, p. 57-72)
} 
reabertura democrática e governo Collor, inseriu-se no debate público pela sua habilidade de mobilizar grupos e legitimar seu discurso. Essa participação da imprensa, suas limitações próprias do campo jornalístico e a atuação de fatores externos a ele, serão discutidas neste trabalho.

A escolha dos jornais O Globo (Rio de Janeiro) e O Estado de São Paulo (São Paulo) ocorreu, exatamente, pela expressão de ambos junto à "opinião pública" e à propalada "credibilidade" com a qual são promovidos, bem como, a capacidade de aceitação e convencimento dos seus leitores acerca do conteúdo publicado nos mesmos, enquadrando-se no que Bourdieu chama de instâncias de sagração. Ou seja, esses periódicos representavam na época, veículos de imprensa com muita credibilidade junto à sociedade brasileira, tanto internamente no campo jornalístico, com reconhecimento por outros jornais, quanto externamente, pela tiragem, número de assinantes e anunciantes. Assim, os impressos analisados possuem forte poder simbólico dentro do campo jornalístico, o que refletiu no debate político da época.

Nossa escolha se deu em razão de serem dois jornais liberal - conservadores do centro sul do país, um representando o estado do Rio de Janeiro e outro representando São Paulo ${ }^{8}$. Essa escolha foi proposital, visto que uma das teses que pretendemos problematizar nesse estudo, é o suposto caráter "conspiratório" das Organizações Globo durante o processo eleitoral para a eleição de Fernando Collor, conforme defendem alguns autores, como Fernado Lattman- Weltman e Venício Lima,. Dessa maneira, confrontando os discursos das duas folhas jornalísticas, podemos identificar elementos capazes de mostrar novos aspectos que não foram analisados em trabalhos anteriores.

O uso da imprensa enquanto fonte de pesquisa justifica-se porque ela apresenta regularidade em suas publicações. Os jornais com os quais trabalhamos possuem edições diárias, de maneira que possibilitam a compreensão da produção dos discursos no contexto em que estavam inseridos e com a linguagem empregada para atingir o leitor da época em que foram escritos.

Outra consideração importante para o uso da imprensa como fonte, é o fato de que muitas vezes os debates do campo político repercutem no campo jornalístico. No caso específico desta pesquisa, em muitos momentos a agenda política de Fernando Collor foi utilizada para estabelecer a agenda da imprensa.

\footnotetext{
${ }^{8}$ Conforme se auto definem os periódicos em questão, de acordo com seus históricos apresentados nos seus acervos digitais, ver $O$ Globo - https://oglobo.globo.com/principios-editoriais/ (acesso em junho de 2017); e $O$ Estado de São Paulo (https://acervo.estadao.com.br/historia-do-grupo/decada_1870.shtm (acesso em junho de 2017) e pela definição de SODRÉ, 2013.
} 
Considerado por muitos autores e analistas políticos da época como uma "surpresa", Fernando Affonso Collor de Mello sagrou-se eleito ao final do segundo turno nas eleições presidenciais de 1989. Essa "inesperada" vitória, mesmo com as principais pesquisas eleitorais indicando seu nome como o mais cotado para receber votos, deu-se em parte porque muitos desses autores consideraram Collor como um outsider político, ou seja, alguém que não pertencia ao campo político ${ }^{9}$.

Nascido no Rio de Janeiro (12/08/1949), filho de Leda Collor e Arnon Afonso de Farias Mello, Collor fez sua trajetória política fora do centro-sul do país, no estado de Alagoas, onde foi prefeito da cidade de Maceió, em 1979. Seu cargo na administração municipal ocorreu ainda sob o período de ditadura civil militar. Paralelamente a sua vida política, Collor também ocupou importantes cargos em veículos da imprensa brasileira, como o Jornal do Brasil ${ }^{10}$ no Rio de Janeiro e a Gazeta de Alagoas ${ }^{11}$.

Em 1982 foi eleito deputado federal pelo PDS. No ano de 1986, foi eleito governador do estado de Alagoas, já filiado ao PMDB, usando como "palanque" a boa fase do governo federal com o Plano Cruzado de José Sarney. Sua vitória para governador atingiu 42\% dos votos válidos e, durante seu governo, procurou travar uma luta moral, lançando-se como o “Caçador de marajás”. Os marajás eram os funcionários públicos que recebiam altos salários em seu estado (ABREU, 2001).

Com base nesses poucos dados, podemos perceber que desde cedo Collor já estava ligado a partidos importantes do período do regime autoritário e na transição democrática. Primeiramente, filiado ao Partido Democrático Social, ex - ARENA, partido que abarcou boa

\footnotetext{
${ }^{9}$ Alguns autores compactuam dessa ideia, tais como FICO, 2017; MENDONÇA e FONTES, 2006; dentre outros, os quais acreditavam ser Fernando Collor de Mello um outsider político. Essa crença advém basicamente do partido pelo qual o político concorreu às eleições: O Partido da Renoção Nacional criado naquela ocasião. Todavia, os autores que defendem essa teoria ignoram totalmente o passado político da família de Collor, cujo avô - Lindolfo Collor, foi político influente na Era Vergas, ocupando a pasta do Ministério do Trabalho e seu pai, Arno Afonso de Farias Mello, chegou ao Senado Federal, tendo sua carreira interrompida após atirar em um desafeto político em sessão plenária da casa. Somente alguém iniciado no campo político, teria a habilidade de "ler" o cenário e disputas partidárias daquele contexto e usar seu capital simbólico acumulado para chegar à presidência.

10 "Desde sempre correspondendo à confiança dos seus leitores, como prometeu no editorial do seu lançamento em 9 de abril de 1891, o Jornal do Brasil acompanhou o processo histórico nacional ao longo de todo o século XX. E se consolidou acompanhando a evolução da sociedade brasileira, mantendo a sua vocação para o pioneirismo, tanto no que diz respeito à qualidade editorial como à produção gráfica, servindo de modelo e referência para o jornalismo brasileiro", disponível em Jornal do Brasil (https://www.jb.com.br/news_archive, acesso em 13/10/2019).

11 "A Gazeta de Alagoas saiu às ruas pela primeira vez no dia 25 do segundo mês do quarto ano da convulsionada década de 30 do século 20. Um domingo. Quis assim Luiz Magalhães da Silveira, seu criador, um jornalista e deputado federal, que vinha combatendo o oligarquismo e havia lançado, em 31 de maio de 1908, o Jornal de Alagoas, que manteria e dirigiria com a mesma finalidade até desfazer-se dele, em 1933, "por circunstâncias políticas", como ele próprio afirmara. Na década de 1950, passou a fazer parte da OAM e se transformou num dos principais periódicos do País", disponível em acervo da Gazeta de Alagoas (http://gazetaweb.globo.com/gazetadealagoas/noticia.php?c=320412, acesso em 13/10/2019).
} 
parte dos políticos ligados ao regime ditatorial e portanto, que comandavam a política brasileira. Depois, filiou-se ao PMDB, ex - MDB (atualmente usando essa mesma legenda). Nesses partidos, o político pôde ter contato com pessoas influentes na política e conhecer a dinâmica do campo político.

Entre ao anos de 1987-1988, no decorrer do fracasso econômico dos planos de recuperação implantados por Sarney, Collor assumiu uma postura opositora ao seu governo, mesmo pertencendo ao mesmo partido, inclusive sendo o único governador, durante a Assembleia Nacional Constituinte, a votar contra a expansão do mandato para presidente da República. Ao término da Constituinte, deu início ao projeto de candidatura à presidência do Brasil (SENADO FEDERAL ${ }^{12}$ ).

O campo político, como qualquer outro campo, segundo Bourdieu, é um campo fechado e estruturado, que possui regras próprias. Onde temos políticos ortodoxos, que são àqueles com maior capital simbólico dentro do campo e por consequência ocupam uma posição de dominação, e os heterodoxos, políticos dominados e que querem atingir uma posição dominante dentro do campo político, precisando, assim, destacarem-se de alguma forma, a fim de obterem o reconhecimento (sagração) de seus pares. No caso de Fernando Collor de Mello, sua escolha de filiação partidária inicial foi logo em um partido cujos integrantes eram dissidentes da ARENA, partido dominante durante todo o período autoritário. Mais adiante, após sua iniciação na política, passou a integrar o PMDB, um dos principais partidos do período da transição democrática, maioria na condução dos trabalhos da Assembleia Constituinte e mesma legenda do presidente da República.

Filho e neto de políticos que exerceram influência em seus mandatos, a família de Collor também soube se destacar no campo jornalístico. Podemos dizer que no Brasil é difícil separar o campo jornalístico do campo político.

O Globo e O Estado de São Paulo, por seu prestígio acumulado ao longo dos anos, sagrados como dominantes na produção de bens simbólicos, no caso aqui, um bem altamente perecível que é a notícia, nos possibilitam verificar sua importância enquanto representantes legítimos dos interesses públicos após a reabertura democrática, momento em que assumiram uma postura mais ativa na vida política brasileira.

As primeiras eleições diretas para presidente, foram realizadas em 1989. Uma das novidades no processo eleitoral, incluída pela Constituição de 1988, foi a necessidade de

\footnotetext{
${ }^{12}$ https://www12.senado.leg.br/institucional/arquivo/historiaoral/fichas-tecnicas/ex-presidente-darepublica/fernando-collor/biografia acesso em 03/07/2019
} 
realização de segundo turno, caso um candidato não obtivesse $50 \%$ dos votos válido em primeiro turno. Assim, os dois candidatos mais votados, disputariam o segundo turno.

À medida em que a campanha eleitoral ia evoluindo, o candidato do PRN, Fernando Collor de Mello, assumia cada vez mais a liderança das pesquisas de intenções de voto. Havia muita especulação e por um momento, chegou-se a acreditar que sua vitória seria ainda no primeiro turno. Ao fim do primeiro turno, Collor sabia que iria enfrentar o candidato do PT, Luiz Inácio Lula da Silva. A campanha eleitoral ficou polarizada. De um lado, tínhamos Lula enfatizando temas como a desigualdade social e buscando o apoio em setores populares organizados. Já Collor, insistiu na necessidade de combate à corrupção, modernização do país e redução de gastos públicos, temas chaves durante toda sua campanha eleitoral (FAUSTO, 2001, p. 290).

Fernando Collor de Mello se tornou o presidente mais jovem do país, com então 40 anos. Sua campanha foi marcada por destacar que não pertencia a nenhum partido grande, e com isso, não teria o apoio de políticos conhecidos no país. Daí o fato de alguns o considerarem um outsider político. Embora concorrendo por um partido inexpressivo, isso não fazia de Collor um inexperiente na política. Ele foi criado no seio de uma família cuja veia política esteve sempre presente. Seu habitus primário, desde cedo o mostrou como são as regras nesse meio. Além disso, adquiriu considerável capital simbólico após adulto, ao seguir os passos do avô e do pai, tanto no campo político quanto no campo jornalístico.

Todavia, após chegar aodomínio do campo político, com sua vitória na eleição presidencial de 1989, Collor mostrou que não soube interpretar tão bem assim as regras políticas, tão pouco soube entender a autonomia do campo jornalístico.

O cenário econômico no momento de sua posse era o pior possível: a inflação chegou a atingir o índice de $80 \%$. Essa era uma das maiores demandas de seu governo.

Nossa pesquisa, apesar de ainda estar em curso, pode oferecer alguns dados parciais acerca da influência do campo político e campo jornalístico no processo de eleição e queda de Fernando Collor. Segundo a teoria dos campos de Bourdieu, existem duas formas de se obter capital simbólico: com o reconhecimento fora do campo a que pertence ou um reconhecimento interno de seus pares, dentro do próprio campo. No caso do político Collor de Mello, o seu capital simbólico foi adquirido a partir da exposição na mídia e posteriormente, dentro do campo político, possibilitando com que chegasse vitorioso ao final do pleito eleitoral de 1989. Todavia, as bases de seu governo não eram sólidas. Muitos políticos abandonaram partidos maiores, como o caso do Partido do Movimento Democrático Brasileiro ao longo do ano de 1989, e filiaram-se ao PRN, partido de Collor. Assim, um 
governo marcado por planos econômicos fracassados, escândalos e corrupção, fizeram com que o político mais jovem a ocupar o cargo de presidente da República, não conseguisse o apoio necessário para lidar com as demandas do jogo político, fazendo com que ele também se tornasse o primeiro presidente a sofrer um impeachment.

\section{Conclusões}

Procuramos aqui discorrer sobre os conceitos de poder; campo político; campo jornalístico e poder simbólico com a intenção de apresentar a possibilidade de uso desses conceitos em trabalhos que versam sobre política e imprensa no Brasil.

Pierre Bourdieu é um autor riquíssimo em suas análises e igualmente difícil de sintetizar. Por essa razão tratamos desses conceitos de forma introdutória. Todavia, é possível perceber que a aplicação de sua teoria da praxis é perfeitamente viável, respeitadas as divergências entre a realidade francesa e a realidade brasileira, especialmente no que se refere à forma de fazer política e a atuação da imprensa. Esperamos ter contribuído assim, para que outros pesquisadores possam igualmente pensar o campo político e o campo jornalístico como campos sociais, analisando os agentes que os compõem e suas relações de dominação e dominantes, verificando como temos na prática a atuação dos mesmos dentro de nossa realidade.

\section{Referências}

ABREU, Alzira Alves de, et al (Orgs.) Dicionário Histórico Biográfico Brasileiro pós 1930. $2^{a}$ ed. Rio de Janeiro: Ed. FGV, 2001.

BOURDIEU, P. A Distinção: crítica social do julgamento. Porto Alegre: Zouk, 2015. . O Poder Simbólico. Lisboa: Edições 70 LDA, 2016.

. Questões de Sociologia. Rio de Janeiro: Marco Zero, 1983.

. Coisas Ditas. São Paulo: Brasiliense, 1990.

Sobre televisão. Rio de Janeiro: Jorge Zahar. 1997.

. BOURDIEU, Pierre. Sobre o Estado. São Paulo: Companhia das Letras, 2014, p. 353, ebook.

FICO, Carlos. História do Brasil Contemporâneo, da morte de Vargas aos dias atuais. São Paulo: Editora Contexto, 2016.

LIMA, Venício A. de. Mídia: Teoria e política. São Paulo: Editora Fundação Perseu Abramo, 2001. 
MENDONÇA, Sonia Regina de. FONTES, Virginia Maria. História do Brasil recente -

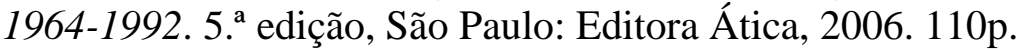

ORTIZ, Renato. O mercado de bens simbólicos. In: ORTIZ, R. A Moderna Tradição Brasileira. São Paulo: Brasiliense, 2011.

. (Org.). Pierre Bourdeiu: Sociologia. São Paulo: Ática, 1983.

PINTO, Céli Regina Jardim. O poder e o político na teoria dos campos. In: Revista Veritas, v.41, n. ${ }^{\circ}$ 162, Porto Alegre: EdiPUCRS, 1996.

SODRÉ, Nelson Werneck. História da imprensa no Brasil. 4. a edição. Rio de Janeiro:

SWARTZMAN, Simon. Bases do autoritarismo brasileiro. Rio de Janeiro: Campus, 1982.

WELTMAN, Fernando Lattman (e outros). A imprensa faz e desfaz um presidente. O papel da imprensa na ascensão e queda do "fenômeno" Collor. Rio de Janeiro: Editora Na Fronteira S.A., 1994.

\section{SITES}

CPDOC Fundação Getúlio Vargas, verbete “constituição 1988”, disponível em: http://www.fgv.br/cpdoc/acervo/dicionarios/verbete-tematico/constituicao-de-1988, acesso em março de 2019.

Gazeta de Alagoas (http://gazetaweb.globo.com/gazetadealagoas/noticia.php?c=320412, acesso em 13/10/2019).

Jornal do Brasil (https://www.jb.com.br/news_archive, acesso em 13/10/2019).

Jornal O Globo (https://acervo.oglobo.globo.com/, acesso em maio de 2017).

Jornal O Estado de São Paulo (https://acervo.estadao.com.br/, acesso em maio de 2017).

Senado Federal (https://www12.senado.leg.br/institucional/arquivo/historiaoral/fichastecnicas/ex-presidente-da-republica/fernando-collor/biografia acesso em 03/07/2019). 